\title{
Speed and Awareness of Network Portability: An Antecedent to Intention to Port among Mobile Phone Users in Southwest Nigeria
}

\author{
Oladele Patrick Olajide \\ Afolabi Yakibi Ayodele
}

Federal University Oye-Ekiti, Ekiti State Nigeria

Faculty of Management Sciences, Department of Business Administration

Ajayi Omobola Monsurat

Akinruwa Temitope Emmanuel

Ekiti State University, Ado-Ekiti, Ekiti state Nigeria

Faculty of Management Sciences, Department of Business Administration

Keywords

Awareness, consumer behavior, intentions to port, Network portability, speed of porting

\begin{abstract}
The study examined the impact of speed and awareness of portability on intention to port among mobile phone users in southwest Nigeria. The study population comprises of staff and students of public universities in southwest Nigeria, the total population for the study was 313,001 and the sample size of 1522 was arrived at by using the Krecie and Morgan sample size table. The sampling techniques used in the study were both probability and non-probability sampling techniques. The non-probability sample techniques used was the homogenous purposive sampling technique for the selection of two universities (one state university and one federal university) from each state in the Southwest, Nigeria; the probability sample techniques were simple random sampling in order for all the elements of the population to have an equal chance of representation. The study analyzed the data through binary logistic regression. The result of the study indicated that coefficient of speed of porting $(\beta=0.321, p<0.05)$ is positive and significant at $5 \%$ level. The results suggested that increase in the rate at which porting can be affected would increase intention to port by about $4 \%$. The coefficient of awareness of porting, which is an indication of level of knowledge of mobile number portability, is also positive and significantly $(\beta=0.451, p<0.05)$ related to consumers intention to port. The study recommends that Government and service providers should take note of the time it will take to port, as it is preferable by subscribers to have less than 48 hours for porting and increase the awareness of portability in order to strengthen the competition and make life better for customers.
\end{abstract}

Corresponding author: Ajayi, Omobola Monsurat

Email addresses for the corresponding author: omobola.ajayi@eksu.edu.ng

First submission received: $2^{\text {nd }}$ November 2018

Revised submission received: $11^{\text {th }}$ March 2019

Accepted: $9^{\text {th }}$ April 2019

\section{Introduction}

The importance of mobile phones to the educated and non-educated Nigerians and the business world has made service provision more lucrative, which gave an opportunity for new service providers to come into the market. As important as the service providers are, the most challenging situations they face is how to satisfy their subscribers (Anderson, Fornnell and Mazvanchery 2004). In recent market, the mobile technology has been competitive and service providers are moving aggressively to attract versatile users by offering some attractive promotions and services (Raman, Hague and Ismail, 2010). Following the launch of mobile number portability (MNP) service by the NCC in April 2013, the cumulative total number of ported lines (both incoming and outgoing) as of March. 2016 was 654,188 even in the presence of mobile phones that have space for two SIM cards (NCC, 2016). This development however poses a question on how awareness affects MNP scheme in Nigeria, with over 190 million population and below 700,000 subscribers have ported so far. Partiksinh (2012) \& Mihir and Divas (2014) in their studies, they 
showed that, though there is a very high level of awareness among students on MNP, there is not much response in terms of increasing the intention to switch service providers, the result therefore revealed that the awareness is not significant with intention to switch. Furthermore, Podvysotskiy (2006), who noted that consumers were often discouraged by long duration, it takes to implement portability. Consumers considered two (2) days' time-to-port as too long. In fact, for some consumers, porting their number within an hour or two is very important, therefore, reducing the time-to-port. One of the key questions around mobile number portability relates to the speed with which numbers are ported. Ofcom (2009a) proposes four options for new mobile number portability (MNP) regimes, two of which include provisions for porting to take place in two hours, and two of which allow for a one-day porting timeframe.

Since the introduction of the MNP, several studies have been conducted on the scheme to examine the determinants of MNP, studies such as; Birgul (2013) in Turkey; Dominic, Joseph and Rogers (2014) in Kenya; Carroll, Howard, Peck and Murphy (2002) in Britain; Shin and Kim (2008); David (2012) in Hong Kong; Xiapong and David (2015) in Britain; Kumaresh and Praveena (2010) in India; Daniel, Alfred and Solomon (2013) in Ghana; Kofi and Oscar (2013) in Ghana; Reddi (2014) in India; Simon and Robert (2015) in Ghana and Pirc (2005) in Spain.

However, Nigeria subscribers seems to be lacking behind in the adoption of the scheme (MNP), as the relative proportion of the population who has ported so far is low, compare to the large population of the country. Moreover, the time it's take to port also needs to be checked as subscribers from existing literature prefers short period of porting. The assessment of these two factors will shed light into how they have affected or affect subscribers from moving from one network to the other, which is the aim of this work.

\section{Literature Review \\ 2.1.1 Conceptual Clarification}

The introduction of number portability is one of the most active policy challenges facing the telecommunications industry worldwide (Daniel, Alfred and Solomon, 2014). The ability to retain a telephone number while switching carrier is known as MNP (Oliver, 2009). Mobile Number Portability means that a customer can keep his/her existing mobile telephone number when he/she changes his/her service provider.

\section{Theory underpinning the study}

Switching behavior includes number of models and theories which explain why customers switch firms. In today's dynamic business environment, marketplace is increasingly being customer-oriented, realizing the importance of keeping customers in a long-term relationship. Though customer retention is crucial, it is equally important to explore and examine the factors that can cause customers to switch service firms. This is simply because, to keep current customers, it is important for firms to understand why customer switches. Conceptually, consumer retention and consumer switching behaviour are two different marketing constructs that have unique theoretical and managerial implications. The subject of Consumer Switching Behaviour (CSB) has gained considerable attention, since the past decade, among scholars and practitioners in the marketing literature, probably, because of its likely impact on the survival, profitability, and growth of the business enterprise (Keaveney, 1995). Morevover, the theory underpining this work is Switching Path Analysis Technique (Model). This model can be used to find out why customers switch their service providers (Roos, 1999). As the name implies, this method focuses on one situation, interaction or encounter that may be noticed by the customers as positive or negative, and therefore it can strengthen or weaken the relationship between customers and the service provider. In the traditional view, the critical incident is held responsible for the customer's decision to switch the service (Roos, 1999).

\subsection{Empirical Review}

\subsubsection{Speed of Porting and Switching Behaviour}

Dorninic, Joseph and Rogers (2014). Studied determinants of consumer switching behavior in Kenya, with sample size of 50 through a stratified sampling technique, using logistic regression to analyse 
the data and the study revealed that only $12 \%$ of the respondents were satisfied with the statutory 3-day porting period. These results were like the findings Podvysotskiy (2006), who noted that consumers were often discouraged by long duration it takes to implement portability. Consumers considered two (2) days' time-to-port as too long. In fact, for some consumers, porting their number within an hour or two is very important, therefore, reducing the time-to-port. One of the key questions around mobile number portability relates to the speed with which numbers are ported. The study of Ofcom (2009) proposes four options for new mobile number portability (MNP) regimes, two of which include provisions for porting to take place in two hours, and two of which allow for a one-day porting timeframe. Both proposed time frame improved on the current requirement for porting to take place within two working days, and both comply with the forthcoming EU requirement for porting within one working day. The benefit to consumers will be greatest if porting takes place within two hours rather than one day. We do not, however, believe that one day is an unacceptably long-time frame for number porting to take place. The online panel research carried out for Consumer Focus asked consumers about the importance of speeding up the transfer process from two days to two hours. 32 percent of consumers responded that this improvement was 'extremely important' or 'very important' to them. This result highlights that a significant number of consumers wish to see a move to two-hour porting. All information needed to understand this study was simplified; but the study muted on the sampling technique used for the study.

\subsubsection{Awareness of Portability and Switching Behavior}

Partiksinh (2012) carried out a study on customer preference for mobile number portability, in which the paper examined the consumer awareness and preference about mobile number portability and try to find out the factors that motivate the use of the MNP. Result suggested respondents were not only aware about the MNP, but they also know the procedure of using the MNP. The outcome of the study suggests that awareness of portability is significant with switching. Mihir and Divas (2014) studied the impact of mobile number portability on the student segment in India, focusing on the effect of MNP. The primary objectives of the study were to study the awareness level of MNP among the students, to explore the brand-switching behaviour of students by accessing MNP, and to understand the factors influencing students towards MNP (Mihir and Divas, 2014). The study showed that, though there is a very high level of awareness among students on MNP, there is not much response in terms of increasing the intention to switch service providers, the result therefore revealed that the awareness is not significant with intention to switch (Mihir and Divas 2014). The study of Redid (2014) focusing on "the impact of MNP on consumer behavior with reference to the Tirupati city of Andhra Pradesh", studied consumer awareness and preference about mobile number portability and tried to find out the factors, which motivated user to opting for MNP. The research design used in the study is of a descriptive nature, with random sampling method being adopted for the distribution of the questionnaire to the respondent. The data were collected from 259 mobile users from different service operators and customer opinion survey was also taken among the selected users. The collected data included personal detail of existing operators, the MNP awareness and motivated factors to choose operator, etc., Data were analyzed by percentage and chisquare test was applied. The secondary data were collected from available literature sources. The finding of the study showed that awareness has positive relationship with switching.

\subsection{Conceptual framework}
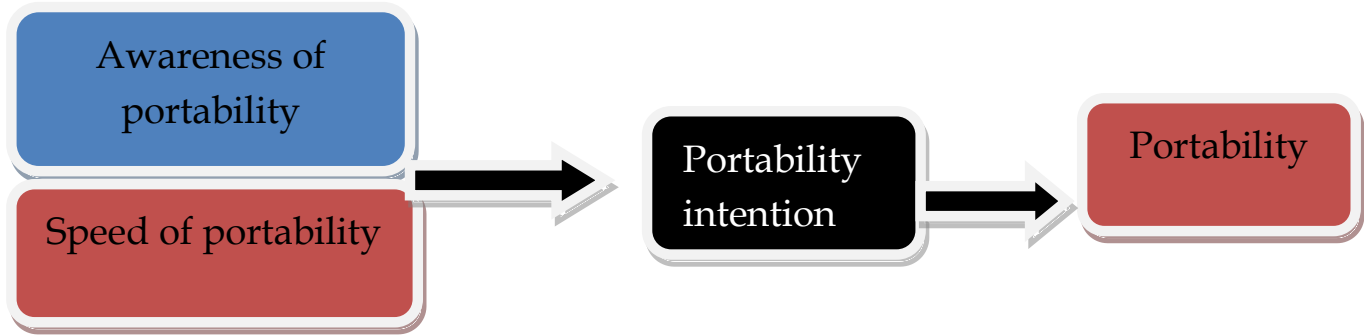

Figure 1. showing the relationship between awareness and speed of porting towards portability Source: Author's compilation (2018) 
The framework as shown in figure 1 described how awareness and speed of portability could induce the intention of movement from one service provider to another which equally could lead to portability.

\subsection{Methodology}

\subsection{Research Design}

This study adopted survey research design to achieve all the objectives of this study. The choice of this research design is borne out of the fact that quantitative researches usually fit with deductive approaches in which there is a theory and or hypothesis, which justifies the variables and the objective of the research. Responses were sought from staff and students of public universities in south west Nigeria on factors enumerated in the research instruments for the purpose of itemizing the incidence of speed of portability and awareness of portability. The research instrument used for this study was the questionnaire adapted from the work of Olatokun and Nwonne (2012). The major modification to the research instrument is in the area of switching for portability.

\subsection{Population, Sample and Sampling Techniques}

The population of the study covered all the staff (academic and non-academic) and students of the selected public universities in Southwest Nigeria. A total number of 37,918 and 275, 083 of staff and students, respectively, constitute the total population of the study

\subsubsection{Sample size and Sampling Techniques}

Mugenda and Mugenda (2003) explained that target population should have some observable characteristics, to which the researcher intends to generalize the results of the study. Considering the enormity of the population of this study, and in order to avoid voluminous data, the total sample size for the study was 1522. This was achieved using the Krejcie and Morgan (1970) approach. The sampling technique used in the study was probability and non-probability sampling techniques. The nonprobability sample techniques used was the homogenous purposive sampling technique for the selection of two universities (one state university and one federal university) from each state in the Southwest, Nigeria, based on the high number of students' enrolment and by JAMB choice, which were a proxy to a large number of staff as well. The probability sample technique was simple random sampling for all the elements of the population to have an equal chance of representation.

\subsection{Method of Data Analysis}

Data for the study were analysed using descriptive and inferential statistics. Descriptive statistics were used to present and analyse demographic data of respondents. The inferential involve the use of binary logistic model, which was applied to all the variables of the study objectives. Parameter estimates of the model were useful in testing the hypotheses of the study following the stated research design. The model was tested using non-linear estimation techniques.

\subsection{Model Specification}

the ratio of the probability that a subscriber is willing to switch network operator to the probability that a subscriber is not willing to switch network operator is written as:

$$
\frac{P_{i}}{1-P_{i}}=\frac{1+e^{X \beta}}{1+e^{-X \beta}}
$$

so therefore,

$$
\mathrm{Li}=\mathrm{Zi}=\mathrm{B}_{0}+\mathrm{B}_{1} \mathrm{x}_{1}+\mathrm{B}_{1} \mathrm{x}_{2}
$$

Where:

$\mathrm{Li}$ is the logit that the natural logarithm of the odd ratio.

$B_{i}=$ the parameters to be estimated

$\mathrm{X}_{1}=$ speed of portability

$\mathrm{X}_{2}=$ awareness of portability

$\mathrm{Zi}=$ number portability 


\subsection{Results}

Descriptive statistics and inter-correlations of speed and awareness of number portability

This analysis was carried out to further establish the suitability of the identified variables for regression analysis. As the results indicated, the mean level the factors have a mean level of 1.51. But the standard deviation value of 0.85 suggested a stable influence of speed and awareness of portability in determining number portability. Based on the descriptive results, the mean level of all the constructs could generally be considered low. The correlation coefficients among the factors were also presented in Table 1.1. The result indicated that inter-correlation among the factors were generally weak. This suggested that the assumption of independence of the variables was not violated.

Table 1.1: Correlation, Means, and standard deviation of speed and Awareness of porting

\begin{tabular}{|l|c|c|}
\hline Variable & Speed of porting (di) & Awareness of porting (d4) \\
\hline Speed of porting (d1) & 1.0000 & \\
\hline Awareness of porting (d4) & 0.1664 & 0.1407 \\
\hline
\end{tabular}

Source: Data Analysis, (2018).

\section{Behavioral Intentions to port among mobile phone users}

Results in Table 1.2 described behavioral intention to port among mobile phone users in public owned universities. Non-derivation of expected satisfaction from mobile phone service was the most important intention driven factors (Mean $=3.34, \mathrm{SD}=0.66$ ) that could make consumers switch to another mobile network. Customer satisfaction generally means customer reaction to the state of fulfillment, and customer judgment of the fulfilled state (Oliver, 1997). There were many benefits for a telecommunication company from a high customer satisfaction level. It heightens customer loyalty and prevents customer churn, lowers customers' price sensitivity, reduces the costs of failed marketing and of new customer creation, reduces operating costs due to customer number increases, improves the effectiveness of advertising, and enhances business reputation (Fornell, 1992).

One of the main factors determining customer satisfaction is the customers' own perceptions of service quality (Zeithamal and Bitner, 1996). Overall, satisfaction refers to the customers' rating of the brand, based on all encounters and experiences (Kim, Chan and Gupta, 2004). Satisfaction can be viewed as a function of all previous transaction-specific satisfaction (Johnson and Sirikit, 2002). Oliver (1997) considered that customer satisfaction means customer reaction to the state of fulfillment and customer judgment of the fulfilled state and introduced the expectancy disconfirmation model for studies of customer satisfaction in the retail and service industries. Oliver (1997) defined satisfaction as a pleasant past-purchasing experience from a product or service given the anti-purchasing expectancy of the customer. In the context of mobile services, service quality had been measured by call quality, pricing structure, mobile devices, value-added services, convenience in procedures, and customer support.

Desire to enjoy better service (Mean $=3.27, \mathrm{SD}=0.59$ ) may also make consumer switch their network to another. These behavioural intentions of consumers were characterized as porting behaviour. With the introduction of mobile number portability in many mobile telecom industries in the world, porting behaviour, had become an important factor that appears to have considerable influence in determining consumer switching decisions (Buehler and Haucap, 2004; Nimako and Niyame, 2015; Shin and Kim, 2008). This was particularly important given that the adoption of mobile number portability by consumers indicated a partial switching situation that can influence a decision to switch carriers completely. The mobile number portability behaviour could influence consumers' switching intention and even actual switching behaviour. 
Table 1.2: Behavioural intentions to port among mobile phone users

\begin{tabular}{lll}
\hline Intention & Weighted Average & S. D \\
\hline It is likely I switch in the future & 3.17 & 0.96 \\
I would switch to enjoy better services & 3.27 & 0.59 \\
I would switch if I could not get expected satisfaction & 3.34 & 0.66 \\
\hline
\end{tabular}

Source: Authors' Field Survey, (2018)

The results (Table 1.3) show that coefficient of speed of porting $(\beta=0.321, p<0.05)$ is positive and significant at $5 \%$ level. The results suggested that increase in the rate at which porting can be affected would increase intention to port by about $4 \%$.

Coefficient of awareness of porting, which is an indication of level of knowledge of mobile number portability, is also positive and significantly $(\beta=0.451, \mathrm{p}<0.05)$ related to consumers intention to port.

Table 1.3: Estimated effect of Speed and Awareness of Portability on the Intention to Port

\begin{tabular}{|l|l|l|l|l|l|l|}
\hline variables & Coef & Std Err & $\mathrm{Z}$ & $\mathrm{P}>|\mathrm{Z}|$ & \multicolumn{2}{|l|}{$95 \%$ Conf. Interval } \\
\hline $\begin{array}{l}\text { Speed of } \\
\text { portability }\end{array}$ & .321 & .128 & 2.51 & 0.012 & .07009 & .5720107 \\
\hline $\begin{array}{l}\text { Awareness of } \\
\text { portability }\end{array}$ & .457 & .118 & 3.80 & 0.000 & .2250241 & .6891871 \\
\hline Constant & .506 & .264 & 1.92 & 0.055 & -.0110001 & 1.023546 \\
\hline
\end{tabular}

LR chi2 $(4)=27.82$

Prob $>$ chi $2=0.0000$

Log likelihood $=-441.816$

$\mathrm{Y}=\operatorname{pr}(\mathrm{d} 5)$ (predict)

$=0.87086$

Source: Authors' Data Analysis, (2018)

Marginal effect after Logit

Form table 1.4 below, it is evident that $1 \%$ increase in the time it's take to port would discourage consumers from porting. It also showed that $1 \%$ increase in the level of awareness of portability will increase the intention to port.

Table 1.4 Marginal effect after logit

\begin{tabular}{|l|l|l|l|l|l|l|l|}
\hline variables & $\mathrm{dy} \backslash \mathrm{dx}$ & Std.Err & $\mathrm{Z}$ & $\mathrm{P}>|\mathrm{Z}|$ & \multicolumn{2}{|l|}{$95 \%$ Conf. Interval } & $\mathrm{X}$ \\
\hline Speed of portability & .0361057 & .01417 & 2.55 & 0.011 & .008339 & .063873 & 1.57951 \\
\hline $\begin{array}{l}\text { Awareness } \\
\text { portability }\end{array}$ & .0514066 & .01287 & 4.00 & 0.000 & .026188 & .076625 & 1.95848 \\
\hline
\end{tabular}

Source: Authors' Data Analysis, (2018)

\subsection{Discussion of Findings}

Speed of porting was positive and significant. Usually, longer process of switching to new service provider would discourage consumers from porting. The result reflects the importance mobile phone users placed on time associated with their communication activities. If time taken to move from one network provider to another after application to port is shorter, consumers' intention to port might increase. The result agrees with Dominic, Joseph and Rogers (2014) and Ofcom (2009a) who found that consumers are encouraged to port if the duration it takes to implement porting is very short.

Awareness of portability was not only found to be positive but also significant. This suggested that increase in awareness of mobile number portability might increase curiosity of consumers and increased intention to port. This result corroborates the finding of Mihir and Divas (2014), Reddi (2014) who also found that consumers ported because of their awareness about mobile number portability (MNP).

\section{Policy Implication}


As network provider are coming to realize the factors that push customers away and also realize the motivating factors, it is pertinent to move all strategies to guide their decisions on these basic factors which will also help market share consistencies and network providers will not have to spend more on looking for new customers, which is more expensive than keeping the old ones.

\subsection{Conclusion and Recommendation}

From the results of data analysis, this study empirically concluded that, speed of porting and awareness drive intention to port among mobile phone users. However, management of porting to another network provider is possible by the regulators in the telecom industry. This implies that porting is not an exclusive customer's affair. Furthermore, the extent to which the consumers were made to be aware of porting could significantly influence the extent of intention to port.

\section{Recommendation}

Government and service providers should take note of the time it will take to port, as it is preferable by subscribers to have less than 48 hours for porting. There is also the need to increase the awareness of portability in order to strengthen the competition and make life better for customers

\section{Limitation and Direction for Future Research}

The mobile telecommunications sector is becoming so dynamic with changing technologies, ever increasing demand, and evolving market structures that it is difficult to empirically isolate the determinants of the MNP. Therefore, this study is vulnerable to the criticism of static analysis that it analyzed determinants of portability mainly from three main concepts. Therefore, the findings of this research may have a limited applicability when service providers and regulators are changing new conditions by altering the terms of service. Future studies may investigate a longitudinal assessment of consumer satisfaction to see the dynamic aspect of the cognitive process

\section{Reference}

Anderson, E. W., Fornell, C., \& Mazvancheryl, S.K. (2004). Customer Satisfaction and Shareholder Value. Journal of Marketing, 68 (8), 172-185.

Birgul, K. (2013). Effect of Mobile Number Portability: Case of Turkey. International Journal of Business and Social Science, 4(14), 200-213

Buehler, S. \& Haucap, J. (2004). Mobile numbering and number portability in Ireland. Journal of Industry, Competition and Trade, 4(3), 223-238, A report to the ODTR, Ovum: London. V

Carroll, J., Howard, S., Peck, J., \& Murphy, J. (2002). A field study of perceptions and use of mobile telephones by 16-22-year olds, Journal of Information Technology, 4 (2), 49-62.

Daniel, O., Alfred, S., \& Solomon, K. (2013). Mobile Number Portability: Its Effect on subscribers. International Journal of Advance Research in Management and Social Sciences, 2(12), 307-320

David, S.Y. (2012). An Analysis of Customer Switching Internet Banks in Hong Kong. The Journal of Global Business Management, 8 (2), 114-125

Dominic, O., Joseph, N., \& Rogers, M. (2014). Determinant of Consumer Switching Behavior in Mobile Telephony Industry in Kenya. International Journal of Business and Management, 3(5), 201-212

Fornell, C., (1992). A national satisfaction barometer: the Swedish experience, Journal of Marketing research, 56 (1), 6- 21

Johnson W. C., \& Sirikit, A. (2002). Service Quality in the Thai Telecommunication Industry: A tool for Achieving a sustainable Competitive Advantage. Management Decision Journal, 40 (7), 693-701.

Kofi, A. B., \& Oscar, O. O (2013). Mobile Number Portability: On the Switching Trends among Subscribers within the Telecommunication Industry in a Ghanaian City. Communications of the IIMA, 13 (4), 7590

Kumaresh. K. \& Praveena, S. (2010). Empirical Analysis of Consumer Switching Behavior Towards.Mobile Number Portability. Journal of Research in Commerce and Management, 1(11), 99-110

Keaveney, S.M. (1995). Customer switching behavior in service industries: An exploratory study. Journal of Marketing, 50 (2), 71-82. 
Kim, H., Chan, H., \& Gupta, S. (2004). Value-based adoption of Mobile Internet, Decision.Support Syst. Journal of management and scientific research, 43, 127-141.

Mihir, D., \& Divas, G. (2014). Impact of mobile number portability on student segmentation in india. An international journal of management studies, 4 (4), 1-6

Mugenda, O. M., \& Mugenda, A. G. (2003). Research Methods: Quantitative and Qualitative Approaches. Nairobi: African Centre for Technology Studies.

NCC. (2016). NCC Industry Statistics. Retrieved from

http://www.ncc.gov.ng/index.php?option=com_content\&view=category\&id=65\&Itemi d=67.

Nimako, S. G. \& Niyame, T.U. (2015). Modelling the antecedents and consequence of consumer switching behaviour in Ghanaian mobile telecommunication industry, international Journal Business and Emerging Markets, 7(1): 37-75

Oliver, L. (2009). Number portability in emerging markets. [Online] Available:

http:// www.iccuk.com/download/papers/NP-in-Emerging-Markets.pdf (October 30, 2013).

Olatokun, W., \& Nwonne, S (2012). Determinants of Users' Choice of Mobile Service Providers in the Nigerian Telecommunications Market. African Journal of Computing \& ICT, 5 (4), 1-14

Oliver, L. (1997). Satisfaction: A Behavioral Perspective on the Consumer, Irwin McGraw-Hill, Boston,

Ofcom (2009a). Consultation document on protecting consumers from fixed-line misselling".Availableathttp://stakeholders.com.org.uk!consultations/protectingconsumers_misselling

Pirc, M. (2005). Mobile service and phone as consumption system - the impact on customer switching. Universitat Pompeu Fabra, Barcelona.

Podvysotskiy, Y. (2006). An investigation of the effect of mobile number portability on Market competition. National University of Kyiv-Mohyla Academy

partiksinh, S.V. (2012). customer preference for mobile number portability. International journal of management and social sciences research, 1 (3), 71-75

Reddi, M. N. (2014). Impact of MNP on Consumer Behavior with Reference to Tirupati City of Andhra Pradesh. Journal of Business and Management, 16(11), 33-39

Roos, I. (1999). Switching processes in customer relationships. Journal of Service Research,2(1), $\quad 68-85$. doi: $10.1177 / 109467059921006$

Rahman, S., Haque, A., \& Ismail, S. A. (2010). Exploring influencing factors for the selection

of mobile phone service providers: A structural equational modelling (SEM) approach on Malaysian consumers. African Journal of Business Management, 4 (13), 2885-2898

Shin, D.H., \& Kim, W.Y (2008). Forecasting customer switching intention in mobile service: An exploratory study of predictive factors in mobile number portability," Technological Forecasting $\mathcal{E}$ Social Change, 75 (6), 854-874.

Simon, G.N., \& Robert, K.N (2015). Inflence of Demography, Reliogiosity and Porting Behaviour of Mobile Subscriber. International journal of business and management, 10 (7), 158-171

Solomon, A.O. (2010). The impact of mobile number portability on TUT student's on-line connectivity. Information systems education conference, Nashville tennese, USA. 27 (1348), 1-13.

Xiaoping, H., \& David, R. (2015). Why Do More British Consumers Not Switch Energy Suppliers? The Role of Individual Attitudes. EPRG Working Paper 1515, Cambridge Working Paper in Economics1525

Zeithamal, A., \& Bitner, J. (1996). Services Marketing, McGraw-Hill, New York. 